\section{Media Studies and the Curriculum}

\section{CHRIS WATSON}

\section{Abstract:}

Media Studies is a popular and vital new addition to the educational curriculum. The term "Media Studies" denotes a "stand-alone" subject that is taught in its own right. The difficulty is to know whether the material which it embraces should be taught in this way or whether it should find a place within the rubric of another field - English, or possibly Technology or Art. "Media Education" is a term used to describe the teaching of media components or modules within existing subject areas.

Another problem relates to the methods required for evaluation. Neither internal assessment of the Sixth Form Certificate, nor the use of the New Zealand Qualification Authority's unit standards will carry the prestige of external examinations such as University Bursary. This impacts on the academic level of students electing to study the subject and the way in which the curriculum must be constructed.

The media are central to the lives of young people. They know this; they rejoice in it. Those of us who teach them, their parents and the politicians who seek to govern their lives, also know this but may not rejoice in it to the same extent. In fact, some parents, some politicians, and, even some teachers, would prefer resistance to acceptance.

They would like children to be inoculated against the pernicious influences of the media. Yet no other subject is taught from such a base. It is the norm for teachers to be enthusiastic about their field of expertise and to attempt to share this enthusiasm with their students. Whilst enjoyment is the key to a lively and vital classroom experience, criticism is not to be ignored for:

Schools are places of critical education whose task it is to create citizens who are able to exercise power over their lives .... Media education is not an end in itself, but one avenue by which children develop the skills which they need to find their own voices and establish the convictions and values necessary for effective participation in democracy. (Quin, 1994)

\section{The Status of Media Studies}

Time and again, the same key issues are raised in discussion. The most significant is the difficulty that teachers of Media Studies are having in persuading politicians and parents that the subject is a worthwhile field of study. Too often it is seen as trivial and undemanding. This perception is fuelled by notions of high and low culture that are not recognized as such by those expressing them. Basically, if the material is popular and directed at the mass it is not seen by some groups in society as valuable.

The concept of the value of élite forms of cultural practice has been defined by Pierre Bourdieu (1984) as "cultural capital". He sees the gaining of an understanding of the "higher arts" as the acquisition of a form of wealth which permits people to "get-on" in terms of status. Thus cultural capital joins noble birth and acquired money as a way of achieving a dominant position in society. For some parents it is the easiest, maybe the only way, for their children to move up in the world. These people, knowing that it is the "high arts" - classical music and literature - that constitute cultural capital, choose to resist the use of school time on a study of popular culture. They prefer that their schools concentrate on the canons of accepted excellence; that is on classical literature and the arts. This is especially true of their feelings about the upper school; about the curriculum for the last years of their children's schooling.

Even in the junior classes such parents will favour the teaching of the "basics". This stems from the belief that it is what employers are looking for. It is generally held that the basics consist of the ability to read, spell and add, and it is assumed that if a student can master these tasks then a job will be available that requires such fundamental skills. Additionally, in recent years, many parents have come to add expertise in computing to the list of essential tasks.

Thus, it is Len Masterman's contention that when one is trying to promote Media Studies, with politicians and with parents, it is counter-productive to mention "Soaps". He believes that when attempting to persuade authorities of the value of media teaching one should concentrate on the "serious" media; he proposes "News" (Masterman, 1980). The whole area is sensitive. It is necessary to explain to politicians, parents, teachers and children the aims and objectives of 
all such teaching. The rationale should be clear. He also advocates avoiding the controversial. He doesn't think that it is worth the risk to the subject as a whole to introduce such topics as "Horror" or the treatment of "Sex".

Conservative parents, and politicians who espouse beliefs in the virtue of the basics and of the classics, are sometimes prepared to tolerate some teaching on the media if that teaching is designed to expose the injurious aspects of media practices, that is, if it demonstrates that the media are incorrect, incompetent and biased. In the United Kingdom, especially, this bias is believed to favour the political "left". It is an approach that has been described as inoculation (Masterman \& Mariet, 1994). It was this underlying expectation that allowed Media Studies to gain its first foothold in Canada and in the United Kingdom. However, when it was discovered that students and their teachers had moved away from such considerations to celebrate the constructs of the media and to appreciate what it was doing, when it was discovered that the bias and ideology that was being exposed was that of the capitalist economy that drove media production, conservative politicians and parents quickly became disenchanted.

Hence, in both Canada and Great Britain moves are afoot to wind back the achievements made in the field of Media Studies teaching to date. In particular its new-found position within core or national curricula is facing challenge. This is especially true when its position within that core is located within the established discipline of English.

Ivor Goodson, in his book School Subjects and Curriculum Change (1987), has traced the establishment of Environmental Studies as a school and examination subject in England. He details the struggle to contain it within Geography (or Biology) and its eventual break-out to autonomous status. He notes that subjects "far from being monolithic entities, are comprised of shifting sets of sub-groups, delicately held together under a common name at particular periods of history" (Goodson, p. 184). The book is based on field research and historical study. It is well worth attention by those who wish Media Studies to be a subject in its own right rather than one that exists as part of an inter-disciplinary study.

\section{The Placing of Media Studies in the Curriculum}

There are three options for the insertion of Media Studies into the school curriculum.

\section{(i) As a specialist subject}

Media Studies can be offered as a stand alone subject. This sometimes happens at the most senior level (or, more often, in the year immediately before the final one). In the first wave of media teaching in schools, during the late 60 s and early 70s, the subject was often called Film Studies, reflectingits content, which at the time was based on the newlydiscovered art status of some films. Nowadays, it may well be called Media Studies in reflection of the broad range of topics which may be encompassed, a key one of which will be Television Studies.

The use of the term Media Studies implies a discrete subject with its own place in the time-table and its own specialist staff. However, Media Studies will achieve a position as a subject at the top school levels only when there is an examination of that name. Unfortunately, unless Media Studies is treated as a subject suitable for the highest level of examinations it does not have the cultural capital to attract the most able students.

\section{(ii) Within another subject}

Media Studies can be placed within another subject with which it is closely allied. It is most often incorporated in English, but there tends to be resistance from some teachers with a degree, or elements of a degree, in Media Studies to this placement. The main substance of their objection seems to be that there will be too heavy an emphasis on texts, to the exclusion of sociological aspects of the study, and that often these texts will be compared across media. It is feared that this comparison will be to the detriment of the visual examples. There is also a suspicion that English teachers, having worked through a classical canon in acquiring their qualifications, will be prejudiced against the popular culture elements that are central to Media Studies.

Even if these fears have substance it is often pointed out that there are pragmatic reasons for accepting location within the English space. These are based on the fact that many English teachers do have the skills of textual analysis that are central to Media Studies (even if such analysis is not the whole story) and that English within the schools does have a secure and central place in the time-table. Conversely, there are few teachers, so far, who have been through Media degree courses at a tertiary institution.

In addition it is often noted that to place any new subject into the overcrowded time-table will prove to be almost impossible in the late twentieth century. 


\section{(iii) Across the curriculum}

The third possibility is to teach it across the curriculum. This option is often favoured for junior classes and by the British Film Institute (BFI), which has been very influential in the development of Film and Media Studies within England and Wales. When Media topics are dealt with in this generalized way, within different subject areas, and by staff who teach other aspects of the school curricula, it is often called Media Education as opposed to Media Studies.

Although the BFI approves of this approach and has drawn up two seminal documents - one relating to Media Education in the primary sector and the other to the work expected in the secondary -it is only at the primary level that cross-curricular work has become general practice. The reasons for such success will be appreciated by primary teachers. Basically, one teacher works with a class of children all the time unless some form of team-teaching allows a small group of teachers to develop individual specialities. Whichever applies, it is relatively easy for a teacher who has been trained in, or knows something about, Media Studies to build the work into the timetable, whenever it seems appropriate to do so. Thus, the technology of the industry might be dealt with in science; the use of story-boards in art; the marketing of a record in music. The relatively simple level of the concepts that will be taught does not necessarily require degree-level knowledge by the teacher, although it has to be admitted that many avoid the topics altogether for lack of any knowledge or training at all.

It should be noted that Language Across the Curriculum has not been a success in England, and some readers might have similar reservations about the success of Taha Maori in New Zealand as a cross-curriculum endeavour. This may help explain the preference of enthusiasts for a stand-alone Media Studies approach.

\section{The Nature of the Curriculum}

Which is to be preferred, a "Spiral Curriculum" approach, or one teaching designated topics at designated times? However an analysis of the Media is taught, a debate about which topic is to be tackled when, and to what depth, soon arises.

Critics have noted that in Media teaching there is a great deal of overlap from year to year, and that certain topics (Advertising is often cited) have been "done to death". These critics tend to feel that the designated curriculum should list the topics to be covered each year in the way planned by the various levels of the unit standards promulgated by the New Zealand Qualifications Authority (NZQA). The Education Review Officers would then ensure that teachers did not introduce anything before they were scheduled to do so. There is, of course, a difficulty in doing this with Media Studies because so many of the topics are inextricably linked - "intertextuality" and "seamless flow" ensure that one aspect will merge into, and blend with, another.

Some teachers use this to talk of Bruner's ideas about a spiral curriculum (Bruner, 1960, pp. 52-54) and justify the repetition, over the years, of certain topics on the grounds that the treatment will become more complex and will be at a greater depth as the children grow older. Certainly, this approach is now commonplace for many other subjects, and there are elements within Media Studies that could lend themselves to such treatment. For example, a study of "representation" can work at a simple level with the youngest children and be enhanced each year with the introduction of ever more complex concepts.

Admittedly, this approach might not work easily for Media Studies because the layers of complexity are not yet clearly defined. It will be necessary to know what concept is dependent on what previous level of knowledge before a hierarchy of treatment for each topic can be worked out. To some extent this is the ambition of those working on the New Zealand Qualifications Authority's unit standards at the moment, and if they can achieve a clear set of statements they will have done an invaluable job in making possible a controlled spiral curriculum approach.

\section{The Nature of Assessment}

In Canada it is the teachers of the High School Diploma, in the year before a student's final year (which is devoted to University Entrance examinations), who have the most scope to develop exciting Media Studies curricula. Similarly in New Zealand much of the mostinteresting and innovative work in Media Studies is being done for the Sixth Form Certificate. Likely reasons for success at this level are, first, that the curriculum is devised by teachers in their own schools, and secondly, that the work being done is examined internally. Unfortunately, it takes an external examination to give a subject the status that it needs to be taken seriously by the community and the most able of students.

It seems that the pattern overseas is to allow the first qualification, taken around the age of 16, to be assessed internally, as in New Zealand, albeit with a more closely directed curriculum from outside, and the second or higher qualification to be examined by an independent body. This examination may include evidence of practical work which is 
assessed separately, and internally, in the way that the art folio is evaluated in New Zealand, but it will also include a written examination testing theoretical concepts in detail.

\section{The Purpose of Practical Work}

Another aspect of relevance to New Zealand which concerns teachers in both Canada and England is the relationship of practice to theory. True, this is an issue within many subject areas, but it becomes particularly crucial in media education because the students and staff so often have widely divergent views about the purpose of practical work. Is it primarily vocational, or should it be regarded as "supportive of theory"?

For the teachers it is generally held that these exercises are intended to make the practices of the media manufacturers "transparent", that is, to ensure that the students understand the complex decisions and the motives behind the decisions which result in the production of a particular media text. For the students there is often the dream of a job in the industry. This latter objective has to be a forlorn hope, but teachers are not thanked for pointing out the futility of any expectation that classroom exercises will lead to actual employment.

Other students may hope that a portfolio of practical work will improve their chances of gaining entry to one of the highly-regarded tertiary courses such as those offered by the Auckland Institute of Technology or Christchurch Polytechnic's School of Broadcasting. It is true that the presentation of an effective portfolio will be useful, but these courses are heavily oversubscribed and entry is very competitive.

It may be that this issue is over-played. Nevertheless teachers feel a responsibility to point out that work in the media industries will owe more to luck and contacts than it will to any practical work undertaken at school.

Even though students love it, practical work isn't all light and joy. Many teachers are apprehensive about operating equipment, and there are many problems of access and acquisition. Scheduling practical exercises in Media Studies is also a worry to many. Furthermore, when expensive equipment is plentifully available, teachers must be wary that the technology does not become an end in itself. Such advanced facilities are often run by people from the industrial arts. They may have the power, but not the theoretical background, and a "turf war" can break out between the English/Media teachers and the technocrats.

For Masterman's planned examination for the Northern Education Board, in the United Kingdom, the idea behind the practical work is that it should feed the written examinations. It should be media-centred, not technology centred. Students should define a topic on which they wish to prepare a report, do the research (sort out an angle, their questions, etc.), and choose a medium through which to present their findings. Although it would be internally marked it would be externally moderated, to ensure that this emphasis persisted. In this way it is hoped that the practical work will inform the theoretical and not become an entity all of its own.

\section{The Work That is Being Done}

Despite the conflicts of basic philosophy that have been outlined, much effective and efficient work is being undertaken in schools around the world, and also here in New Zealand. Locally, Helen Martin's Critical Media Studies: A Teacher Handbook gives a background to recent developments and includes detailed examples of work that could be attempted at all levels of schooling.

\section{(i) In the junior (primary) school}

In England and Wales, teaching in the primary school is cross-curricular, and when it occurs invariably owes much to Cary Bazalgette's BFI syllabus which was designed to promote cross-disciplinary teaching in the secondary school, but which was readily accepted by many primary teachers as relevant to their needs.

Her key definition of what actually constitutes Media Education is as follows:

Media education ... seeks to increase children's critical understanding of the media - namely television, film, radio, photography, popular music, printed materials and computer software. How they work, how they produce meaning, how they are organized and how audiences make sense of them, and the issues that media education addresses. [It] aims to develop systematically children's critical and creative powers through analysis and production of media artefacts. This also deepens their understanding of the pleasure and enjoyment of the media. Media education aims to create more active and critical media users who will demand, and could contribute to, a greater range of diversity of media products. (Bazalgette, 1989, p. 3)

Based on these principles she prepared a model which has been reproduced in the document designed by the British Film Institute for Secondary School use (Bowker, 1991). 
At primary school level in New Zealand, some teachers, often the younger ones who have come through the burgeoning media courses in their own secondary schools and in the universities, may teach some aspects of the media curriculum.

Figure 1 Signpost Questions on Media Education

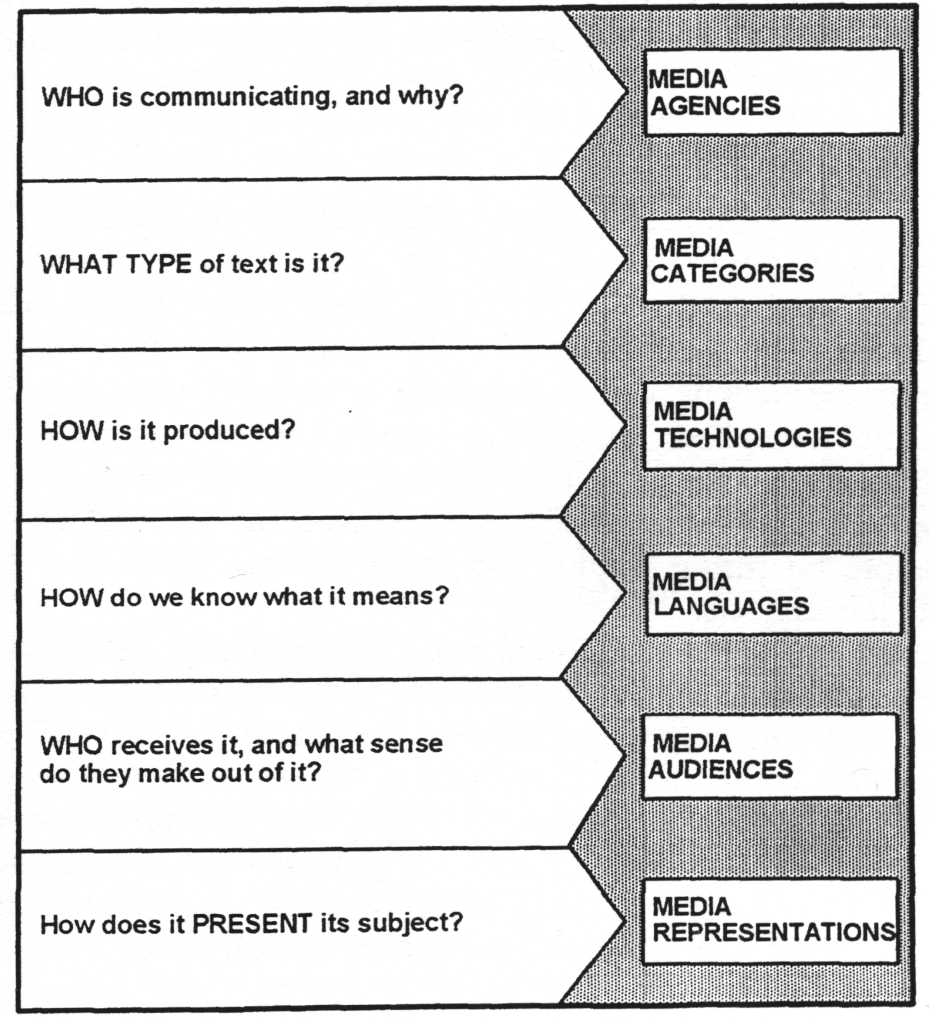

Source: Bazalgette, 1989, p. 8.

At present it is the print medium which is the one most often covered, largely because the Newspapers in Education initiative promulgated by the nation's newspapers and such pioneers as Nigel Evans of The Dominion, have provided excellent resources. Many newspapers also run a page for schools each week, and many encourage local school children to contribute to them.

\section{(ii) In the senior (secondary) school}

Life in the senior schools of many countries is divided into classes that are preparing for external examination and those that are not. Usually students' work in the first few years of secondary school is internally assessed and the work of the final years is subject to external examination. Occasionally this allows the internally assessed work to be the subject of a locally developed curriculum but, more usually, teachers will be expected to work within the bounds of an externally devised set of guidelines.

\section{Great Britain}

Secondary school students in the United Kingdom aged 11 to 15 are in classes that are not examined externally. Their work is governed by the National Curriculum which seeks to define what must be taught by schools until the requirements of the examination system take over. However, the National Curriculum deals in "proper" subjects, and Media Studies has never been included as a subject in its own right. There are four core areas with eight foundation subjects, all based around the traditional subjects rather than around broad areas of knowledge. Media Education, for junior pupils, had to be squeezed into the core and foundation subjects.

As a result of the addition of more and more new subjects into the existing framework the junior school day soon became overcrowded, and certain traditional elements such as the classical theatre of William Shakespeare began to get squeezed out. This has led to a reconsideration of the "non-essential elements" with a view to removing them from the curriculum, a movement which is posing a threat to the tenuous placement of Media Education within English, even though the Cox Report of 1989 had required that Media Education be a part of the system.

In the United Kingdom, at ages 16 to 18 or so, the exam prescriptions take over from the provisions of the National Curriculum. The first of these is the GCSE (General Certificate of Secondary Education) which is traditionally tackled at age 16 . At this stage of a child's school career, specialist work gets done and Media Studies takes over from the more generalized Media Education.

Usually Media Studies is offered where English is strong and well staffed. There is a squeeze on time, however, for Media Studies is still regarded as peripheral. This stress on the time available is often managed by putting half the time for teaching Media Studies into the 
English syllabus, where it is one option. By adding about half as much time for the rest of the syllabus the students can use their knowledge in two examinations. This is not considered odd

Canada

The position in Canada is similar, although the assessment for the High School Diploma is undertaken by the school itself. However, the provincial government decrees how this shall be done and, to some extent, what shall be studied. At Grade Eleven three English credits must be obtained, and at this level Media Studies will make up about a third of the English study. It may also stand as a subject in its own right, but if it does so, as in the United Kingdom, it is regarded as an extra. There are certain subjects that are mandatory. These comprise a kind of top tier of importance. Despite the attention paid to Media in Ontario, the province regarded as a model for this development of the curriculum, Media Studies is not one of those subjects that rates compulsion.

\section{New Zealand}

For New Zealand, an internal assessment procedure is used for Sixth Form Certificate and schools are given much autonomy in deciding what they will teach. Many innovative schemes for the teaching of Media Studies at this level have been devised, although they are very variable both in content and quality.

The New Zealand Qualifications Authority is working to codify the practice by providing a series of unit standards from which teachers will be able to select those which are appropriate to their own level of expertise and to their students' requirements. NZQA's system of assessment will then sanctify the work in a formal way. In accordance with NZQA's commitment to "seamless education", the standards will be at varying levels. For example, as well as covering the work tackled at the sixth form, they may replace that undertaken for Bursary within the English syllabus, and possibly even go so far as to satisfy tertiary expectations. Although they will concentrate on the senior school initially, the standards will eventually cover the work that could be done by junior classes as well.

\section{(iii) Advanced level courses}

Most countries with an examination system have a top-tier of examinations designed to select students suitable for work at a tertiary institution. In New Zealand this is the University Bursary (and Scholarship); in the United Kingdom it is Advanced Level, and in Canada it is University Entrance.
Great Britain

In the United Kingdom, Media Studies is the subject of two papers at Advanced Level. The existing papers have been criticized as too academic and "not suited to the realities of the classroom" (Jones, 1993). Len Masterman has been commissioned to work on a new syllabus for the NEB (Northern Examining Board) which is expected to correct this over-emphasis on the regurgitation of received wisdom. His examination will not be content based. The first section of Masterman's two-paper exam will be devoted to Practical Criticism, and the second to designated Depth Studies. In addition to these two written examinations there will be $20 \%$ of the total marks given to internally assessed practical work.

The idea is for students to develop and demonstrate their "critical autonomy". The examination will be designed to try to avoid the repetition of teachers' notes on topics like "The News". It is hoped that students will state principles and apply them to a programme that they have seen recently. Basically, Masterman believes that the curriculum should be based on children's understanding of life and on their needs to control it, not on the requirements of the tertiary institutions.

Canada

In Ontario, students wishing to gain admission to university choose six courses from a list of subjects, each of which carries an "academic credit point". The subjects available would not normally incorporate a media course. However, it is possible for Media Studies to be one of the five credits within English which together make up the mandatory English academic credit point, even though Media Studies is not accepted, as a subject in its own right, as one of the six credits needed for University Entrance.

\section{New Zealand}

The situation in New Zealand is analogous to that in Canada. Students wishing to demonstrate expertise in Media Studies have no specialized paper at Bursary level. They must tackle media topics, within English and within the optional section at the end of the paper where they may choose just one question to answer. In 1994 that was from a section designated Film, where candidates were offered the chance to compare a film with a book; the opportunity to detail the elements of story-telling used by a film-maker other than through visual images [my emphasis]; an invitation to comment on the representation of New Zealand culture in New Zealand films; or the opportunity to discuss the use of visual imagery in a feature film of the student's choice. 
Attempts to get a pre-university Bursary paper devoted exclusively to Media Studies, as in the United Kingdom, have not been successful. There appears to be little sympathy within the Ministry of Education for the idea (Watson, 1992). The main thrust is to promote the unit standards devised by the NZQA in the expectation that they will facilitate the multi-level seamless education that is currently favoured for the future. Thus, public servants won't say so, but it seems that political pressure is needed to insert new subjects into the limited range of options at this level. The way that Japanese Language became a Bursary subject could be regarded as a model. The proposal to include it was backed by Foreign Affairs, businessmen and the Japanese Embassy. If Media Studies is to be included at Bursary level, strong pressure from the Media industries will be required. As they don't see the schools providing a training ground for future staff this means that they would be asked to support a programme that was often critical of their practices. Nevertheless there are allies available. The eTV service, headed by Robert Boyd-Bell; Newspapers in Education, by Nigel Evans; and the New Zealand Film Commission, through Lindsay Shelton, could be expected to provide a core of industrial pressure that might have the necessary clout to support lobbying by the National Association of Media Educators (NAME).

Another reason for the lack of enthusiasm on the part of the Ministry and NZQA for putting Media Studies into a Bursary framework possibly stems from the fact that there are two other initiatives currently underway which would have an effect on such plans.

One involves the development of Visual Language as one of three "strands" within the new English curriculum that will cover all levels of the school through to the Bursary English examination. To give Media Education such an extensive position within the English syllabus is to approach the Canadian model. Media educators will see the proposal as a big improvement on the present situation.

Much more interesting work than a study of "book-to-film" is outlined in the various Teaching and Learning proposals beneath each of the achievement objectives in the English curriculum. For example under the rubric of "Viewing: exploring language, thinking critically", teachers are advised to study the language of film, by watching "selected scenes ... from a television soap opera, several times", and then, in groups, to "watch for and discuss the characters in terms of their settings, appearance and dress, body language, gestures and expression, dialogue and the use of voice, attitudes and behaviour" (Ministry of Education, 1994, p. 114). It must be said that to do this through the medium of television soap opera rather than through an actual film is not the suggestion of a cinema purist!

Such proposals will not have a smooth passage into the classroom. As this article has demonstrated, the English curriculum has been a site of contestation between educational progressives and conservatives over time, and around the world. The battle has been joined in New Zealand as well. Conservative, self-appointed commentators, like Agnes Mary-Brooke of Nelson, are vociferously opposed to including an analysis of the artefacts of popular culture within a subject like English. As they see it, finding a place for such modern concerns can only be to the detriment of space for works from the classical canon which they would privilege. They have found some support within Cabinet. The original revision, which gave much space to Media Education, within English, was rejected by the Minister of Education. Nevertheless, the Visual strand has survived to the post-battle second phase and made it to the draft presently under consideration. The response of both primary and secondary school respondents to this proposed curriculum has indicated enthusiasm for the inclusion of the visual strand, but at the same time concern about their ability to teach it without considerable support and in-service training.

The second initiative that forestalled the moves to have Media Studies examined at Bursary level was the concurrent development by the New Zealand Qualifications Authority of a set of unit standards specifically for a subject called Media Studies. As with the new English curriculum these unit standards were to encompass the whole of schooling and the more complex ones could even require work at the early tertiary level.

NZQA devised its unit standards as the result of a process of country-wide consultation undertaken by Philip Tremewan during 1994. The various drafts have been mediated by feed-back from media educators throughout the country and are still open for comment, with a view to trialling them during 1996. Also, during 1996, a system of moderation will be set up in the expectation that standards can officially be adopted in 1997 when the Qualifications Framework is scheduled to be fully in place. These standards are designed for various levels in the school extending into the first years at tertiary institutions.

The National Association of Media Educators, which was a contributor to the NZQA development process, has taken the NZQA work a stage further by proposing a modified version of it as a de facto curriculum to be used as a guideline for schools designing their own stand-alone Media Studies programmes. Their working draft curriculum 
of March 1995 is a succinct and effective document. It is more clearly informed by the literature and by current developments in the teaching of Media Studies at the tertiary level than the much larger document dealing with the Visual strand of the English Curriculum Statement. Perhaps this is not surprising, for the Ministry approach is to adapt the field to an existing subject area, in the manner of the cross-curricula Media Education model, whereas the NZQA and NAME proposals are for the stand-alone subject, Media Studies.

Politicians are ambivalent about their plans, but if NZQA's modular unit standards were to replace Bursary, the required status for Media Studies might then be attained. The subject would acquire the cultural capital that would make its study attractive to all students - and to their parents. But, if Bursary continues to co-exist with other qualifications then it will be that examination which will retain pre-eminence. It is for this reason that the Bursary option will have to be pursued if the most able students are to be attracted to Media Studies. In order to ensure that Media Studies becomes a field of study that is as challenging as it is enjoyable, it is essential that the brightest students are recruited. Only in this way will whole classes reach the level of critical skill required by Robyn Quin, Len Masterman, and the National Association of Media Educators in their vision for the future.

\section{References}

Bazalgette, C. (1989). New developments in media education. In F. Potter (Ed.), Reading, learning, and media education. Oxford: Blackwell, p. 3.

Bourdieu, Pierre (1984). Distinction: a social critique of popular taste. London: Routledge Kegan Paul.

Bowker, Julian (1991). Secondary media education: a curriculum statement. London: British Film Institute.

Bruner, J. (1960). The process of education. Cambridge, Mass: Harvard University Press, pp. 52-54

Duncan, Barry (1993, July 6). Chairperson, Ontario Media Literacy Association at the School of Experiential Education. Interview, Toronto.

Goodson I. (1987). School subjects and curriculum change: studies in curriculum history. London, Falmer Press, p. 184

Jones, Terry (1993, August). Interview, London.

Martin, Helen (1994). Critical media studies: A teachers' handbook. Auckland: Media Studies Fellowship.

Masterman, L. (1980). Teaching with television. London: Macmillan.
Masterman, L. \& Mariet F. (1984). Media education in 1990s' Europe. Strasbourg: Council of Europe Press.

Ministry of Education. (1994). Visual language: Viewing. English curriculum statement. Wellington: Ministry of Education, p. 114, Example 3.

Quin, Robyn (1994, Summer/Fall). Teaching media: Paradigms for future instruction. Media Matters,.

Watson, C. (1992, May). Media studies as a Bursary subject. Script\#25. Auckland.

\section{The author}

Chris Watson is a Senior Lecturer in the Educational Psychology Department of Massey University, with a major interest in Media Education. He has conducted research on adolescents' patterns of media consumption, and prepared various reports for the Broadcasting Standards Authority on the nature and quantity of violence and sex on broadcast television, as well as a focus group evaluation of the programme Sophie Lee's Sex. 